Secuencia (2014), 89, mayo-agosto, 195-219

ISSN: 0186-0348, ISSN electrónico: 2395-8464

DOI: http://dx.doi.org/10.18234/secuencia.v0i89.1231

\title{
Miguel Esparza
}

Estudiante del doctorado en Historia Moderna y Contemporánea del Instituto de Investigaciones Dr. José María Luis Mora.

\section{Resumen}

Las sequías son fenómenos ambientales a los que se les han adjuntado una serie de fenómenos sociohistóricos de orden ideológico y operativo que han intensificado y producido la escasez de agua que actualmente viven las grandes ciudades. El presente documento tiene la intención de mostrar qué es el fenómeno de la sequía, cómo se manifiesta una sequía, cuáles son los daños que provoca, qué acciones implementa el gobierno para combatirla, de qué manera se podría resolver este problema en el futuro y de qué forma se representa este fenómeno en México.

Palabras clave:

Sequía; escasez de agua; trasvase; desalinización.

Fecha de recepción: junio de 2012
Fecha de aceptación:

enero de 2013 


\title{
Drought and Water Shortages in Mexico. Current Status and Future Prospects
}

\author{
Miguel Esparza
}

Doctoral student in Modern and Contemporary History Research at the Instituto de Investigaciones Dr. José María Luis Mora.

\begin{abstract}
Droughts are environmental phenomena to which a number of socio-historical phenomena of an ideological and operational order are attached, which have intensified and produced the water shortages currently experienced by large

menon of drought, how a drought occurs, the damage it causes, the actions government implements to combat it, how this problem could be solved in the future and how this phenomenon is represented in Mexico.
\end{abstract} cities. This paper seeks to explain the pheno-

Key words:

Drought; water shortages; water transfer; desalination.

\section{Final submission: Acceptance:}

June 2012 January 2013 


\title{
La sequía y la escasez de agua en México. Situación actual y perspectivas futuras
}

\author{
Miguel Esparza
}

\section{INTRODUCCIÓN}

$\mathrm{P}$ artiendo del punto de que en una sociedad los diarios esparcen las ideas que conforman la mentalidad de la época, este estudio tratará de realizar una "representación" de la problemática actual del agua en México analizando los discursos y las crónicas de la prensa que han centrado su atención en el fenómeno de las sequías y la escasez de agua en México. Se tomará como base teórica lo propuesto por Roger Chartier, quien establece que una representación grosso modo es la apropiación de un texto y su posterior interpretación, las cuales dan lugar a una representación de la mentalidad de una sociedad en un momento y lugar determinados. ${ }^{1}$

El presente documento tiene dos objetivos principales; el primero es evidenciar que los efectos agravados de las sequías y la escasez de agua no sólo son por causas naturales, sino también por causa de factores sociales donde se destacan las malas políticas de administración y uso de las reservas de agua, el paradigma obsoleto del trasvase como solución, la falsa idea

\footnotetext{
${ }^{1}$ Chartier, Mundo, 2005, pp. 45-62.
}

de la abundancia de agua y la fragmentación política. El segundo es mostrar que en la actualidad existen alternativas tecnológicas que pueden solventar la problemática de la falta de agua, aunque esto requiere el establecimiento de un nuevo paradigma.

En la actualidad la sequía es uno de los problemas que más daños está provocando en la sociedad mexicana, principalmente en el norte del país, donde históricamente se presenta dicho fenómeno meteorológico. La sequía es un fenómeno natural cuya característica principal es la ausencia o la disminución de precipitaciones pluviales durante un periodo que se estima lluvioso, y esta mengua en la cantidad de agua existente y disponible para el abasto humano desencadena una serie de dificultades derivadas de la escasez del líquido que finalmente crea conflictos y desastres sociales.

\section{ENTENDIENDO EL FENÓMENO \\ DE LA SEQUÍA}

De forma simple, una sequía se define como la disminución o la ausencia de precipitaciones pluviales respecto al índice anual y, contrario a lo que se supone, es 
un evento normal y recurrente que se presenta de forma cíclica en todas las zonas climáticas del mundo, aunque con mayor intensidad y recurrencia en las zonas áridas y semiáridas. ${ }^{2}$ En nuestro país estos fenómenos ocurren en promedio "cada 20 años", ${ }^{3}$ y cuando se presentan provocan un desbalance hídrico en el ciclo del agua, pues la disponibilidad del recurso es insuficiente para satisfacer las necesidades de los seres vivos. Una sequía puede durar en promedio de uno a tres años, y termina cuando las lluvias regresan y se recupera el índice normal de precipitación y se restablece el funcionamiento de los cuerpos de agua.

La sequía se clasifica principalmente en tres tipos: meteorológica, agrícola e hidrológica. Estas distintas tipologías de sequía "identifican el principio, el final y el grado de severidad de la misma". ${ }^{4}$ Todos los tipos de sequía tienen origen en la misma causa: la falta de lluvias, por tanto, cuando "únicamente se toma en cuenta la lluvia", estamos hablando de la sequía meteorológica. Es a este tipo de sequía a la que se le atribuye el inicio del desequilibrio hidrológico, pues es cuando se percibe una interrupción en el temporal por una o más estaciones; este tipo de sequía es difícil de precisar, puesto que sus efectos o incidencia son diferentes dependiendo del lugar donde ocurra; por ejemplo, en Bali la sequía meteorológica se define como "el periodo con ausencia de lluvia en seis días", mientras que en España se considera como sequía meteorológica un periodo que puede alcanzar

\footnotetext{
${ }^{2}$ Esquivel, "Lluvia”, 2002, pp. 24-42.

${ }^{3}$ Cerano et al., "Reconstrucción”, 2009, pp. 27-44

${ }^{4}$ Contreras, "Sequías", 2005, pp. 118-133.

${ }^{5}$ Velasco, "Importancia", 2006, p. 23.
}

hasta dos años consecutivos sin precipitaciones. $^{6}$

La sequía agrícola, por su parte, se suscita después de una sequía meteorológica, y ocurre "cuando no existe humedad suficiente en el terreno para el cultivo determinado en un momento particular de tiempo". ${ }^{7}$ La sequía agrícola afecta principalmente a la agricultura, pues el terreno, por la falta de lluvias, las altas temperaturas y la evaporación, pierde totalmente su humedad normal, impidiendo con ello el desarrollo exitoso de cualquier plantío. M. S. Kulik define la sequía agrícola como el "periodo durante el cual sólo hay 19 $\mathrm{mm}$ de agua disponible en los primeros $20 \mathrm{~cm}$ de suelo".

Por último, se menciona que hay una sequía hidrológica cuando por la falta de lluvias durante una o más estaciones el nivel de los ríos, lagos y demás embalses superficiales y subterráneos comienza a bajar paulatinamente, incluso hasta agotarse por completo. ${ }^{9}$ En su ciclo normal, el río Okavango presenta una importante cantidad de agua en su caudal y durante la temporada de lluvias; este caudal puede desbordarse e inundar extensas zonas durante muchos meses, sin embargo, al suscitarse una sequía, su caudal se puede reducir considerablemente o secarse por completo durante varias estaciones, y volver a recuperarse cuando de nuevo llegan las lluvias. ${ }^{10}$ Las presentes definiciones muestran los alcances y las manifestaciones de los principales tipos de sequía, que al ser contextualizados con otros datos y

\footnotetext{
${ }^{6}$ Marcos, "Sequía”, 2001, pp. 59-80.

${ }^{7}$ Esquivel, "Lluvia", 2002, p. 25

${ }^{8}$ Kulik, citado en Marcos, "Sequía”, 2001, p. 61.

${ }^{9}$ Meulenert, "Condiciones", 2006, pp. 1-18.

${ }^{10}$ Ashton y Neal, "Overview”, 2003, pp. 31-63.
} 
con otros problemas de nuestra realidad, nos permitirán entender por qué históricamente, cuando se presenta la sequía, se padecen graves afectaciones a las actividades humanas y a los bienes.

México es un país vulnerable a las sequías porque gran parte del país $(52 \%)$ está catalogado como árido o semiárido. ${ }^{11}$ Es decir, catorce estados del territorio nacional presentan zonas áridas y semiáridas. ${ }^{12}$ Estas áreas son territorios más susceptibles al fenómeno de las sequías porque son sitios con baja precipitación pluvial a lo largo del año (un mes para las zonas áridas y de uno a tres meses para las semiáridas), y esta condición provoca que las sequías se presenten de manera más recurrente y que haya mayor presión sobre el agua existente cuando ocurren. ${ }^{13}$

Estados como Chihuahua o Coahuila tienen promedios anuales de lluvia de 462 y $379 \mathrm{~mm}$ respectivamente, que comparados con el índice de Tabasco (2 $102 \mathrm{~mm}$ ) resultan índices pluviales bajos. ${ }^{14}$ Asimismo, en estas zonas se encuentra $32 \%$ del agua superficial, se concentra $77 \%$ de la población nacional y se produce $85 \%$ del PIB. ${ }^{15}$ Es de notar que a pesar de la condición de aridez y de las pocas precipitaciones, existe una alta densidad poblacional y una gran actividad económica en esta zona del país, esto ha sido posible porque se ha hecho uso de la tecnología para construir grandes obras hidráulicas que han permitido modificar, almacenar y ejercer control sobre los distintos cuerpos de agua, con lo cual se ha podido hacer frente

${ }^{11}$ Salinas et al., "Aridez”, 1998, pp. 29-44.

${ }^{12}$ Ruiz y Febles, "Desertificación”, 2004, pp. 1-11.

${ }^{13}$ Verbist et al., Proyecto, 2010, pp. 2-19.

${ }^{14}$ CONAGUA, Estadísticas, 2009, p. 28.

${ }^{15}$ Guerrero et al., "Agua”, 2009, pp. 16-23. (en parte) a las sequías y se ha asegurado (relativamente) el abastecimiento de agua y, con ello, la permanencia del ser humano en las zonas áridas y semiáridas del territorio nacional.

\section{El PARADIGMA DE LA ABUNDANCIA}

Aunque desde hace años el gobierno y los medios han señalado en repetidas ocasiones que el agua es cada vez más escasa, al parecer, aún no se toma conciencia del problema, pues las personas, cuando abren el grifo, no toman en cuenta lo escaso del recurso ni lo que cuesta, o todo lo que implica abastecer a las ciudades. Sólo se tiene noción de lo importante que es el agua cuando por alguna causa el servicio de abastecimiento se suspende.

Una de las condiciones que han agravado los efectos de las sequías en los últimos 100 años es la idea de que el agua es un recurso abundante. En efecto, a principios del siglo XX se comenzaron a construir grandes obras hidráulicas (presas) bajo el paradigma del progreso; estas obras fueron consideradas construcciones que vendrían a ponerle fin a las sequías, pues con el almacenamiento de grandes volúmenes de agua se contaría con una reserva de la cual se podría echar mano cuando una sequía se presentara; asimismo, se pensaba que con las presas se extendería la agricultura de riego, el crecimiento demográfico y la producción de electricidad. ${ }^{16}$

$\mathrm{Al}$ extender la frontera de riego habría una mayor producción agrícola como reserva de alimentos para paliar los efectos de una sequía en caso de que este fenó-

${ }^{16}$ Aboites, Birrichaga y Garay, "Manejo", 2010, 
meno ocurriera. De igual forma, la producción de electricidad hizo posible dotar de agua a las ciudades, con lo cual creció la población urbana y se elevó el estándar de vida, pues por medio del bombeo "cada habitante podía recibir hasta 100 litros diarios para satisfacer sus necesidades", ${ }^{17}$ dando lugar a que existiera mayor demanda de agua, lo que a la larga ha provocado su desperdicio y, con ello, una mayor presión sobre el líquido disponible.

De acuerdo con Francisco Peña, la expansión capitalista que modificó cuencas y cauces con la idea de que el agua era un bien inagotable que debía ser dominado para favorecer las necesidades de la creciente sociedad, hoy en día ha provocado una grave "crisis del agua". ${ }^{18} \mathrm{Al}$ respecto, César Nava menciona que la problemática que vive el país en materia de agua se debe a que el balance entre el consumo y las reservas disponibles está roto, es decir, se consume más de la que se recarga, y esto puede sintetizarse en tres rubros: distribución inequitativa, sobreexplotación y contaminación. ${ }^{19}$

Las cifras referentes a la distribución inequitativa que maneja Nava indican que en la zona norte se cuenta con una dotación anual de $1835 \mathrm{~m}^{3}$, cifra catalogada como "muy baja", mientras que en la zona sur se cuenta con una disponibilidad de $13290 \mathrm{~m}^{3}$ al año. En lo correspondiente a la sobreexplotación, Nava menciona que "la extracción del líquido es superior a la recarga al menos en 10\%”. De igual forma sugiere que los acuíferos administrados por el gobierno se encuentran sobreexplotados, pues de ellos se extrae $60 \%$ del

${ }^{17}$ Ibid., p. 26.

18 Peña, "Lucha", 2005, p. 220.

19 Nava, “Agua", 2008, pp. 59-81. agua subterránea. Por último, en lo relativo a la contaminación se señala que " $27 \%$ del agua presenta calidad satisfactoria [...] 49\% se encuentra poco contaminado, y $24 \%$ se encuentra altamente contaminado [...] sólo $5 \%$ presenta excelente calidad". ${ }^{20}$ La mala distribución del agua, aunada a la sobreexplotación y a la contaminación, reducen significativamente la cantidad de líquido disponible para el consumo, es decir, el agua es cada vez más escasa, situación que se agrava cuando se sufre un episodio de sequía.

Sequía y escasez pudieran parecer lo mismo, pero son conceptos que representan fenómenos diferentes; mientras que la sequía es un fenómeno natural que termina (en todas sus manifestaciones) cuando llegan las lluvias y se recupera el nivel normal de los cuerpos de agua, la escasez puede persistir con o sin lluvias y sin que ocurra una sequía, ya que este fenómeno se debe a la acción humana y consiste en extraer y consumir más agua de la que se logra recargar y de la que se encuentra en existencia y disposición.

En suma, se puede concluir que México es un país vulnerable a los efectos de las sequías, primero por el hecho de que gran parte de su territorio es árido o semiárido, por lo que percibe poca cantidad de lluvias; segundo, porque la mayor parte de su población está concentrada en las zonas donde menor cantidad de agua superficial existe; tercero, porque las grandes obras hidráulicas construidas a lo largo del siglo Xx crearon una sensación de abundancia que hoy en día ha sido sobrepasada por el dispendio, y cuarto, debido a la sobreexplotación, el desperdicio y la contaminación, el agua disponible para

${ }^{20}$ Ibid., pp. 61-62. 
atender las necesidades de la población en condiciones normales se reduce significativamente, situación que tiende a agravarse a extremos críticos cuando por efecto de una sequía se interrumpe el ciclo normal de lluvias.

LA PERCEPCIÓN DE LA SEQUÍA Y LA ESCASEZ EN EL IMAGINARIO SOCIAL

Cuando sequía y escasez se conjugan, por lo general deviene una catástrofe social, pues con la sequía la situación de escasez termina por colapsar; sin embargo, resulta difícil percibir una sequía, ya que es

un fenómeno poco espectacular, y quizá por esto no llama mucho la atención y se tiende a subestimarlo. Se comporta como los enemigos silenciosos: avanza sigilosa y progresivamente y uno se da cuenta de su presencia cuando su ataque ya está en marcha. ${ }^{21}$

Un episodio de sequía puede estar presente en una población y la sociedad no la percibiría si se cuenta con el agua suficiente en sus embalses para abastecer el consumo habitual de la población hasta el regreso de las lluvias; esto puede ser posible, si dicha población se surte por medio del trasvase de agua de una cuenca lejana donde la sequía no esté golpeando. Percibir el principio de un fenómeno de sequía es complicado, pues incluso se pudiera confundir con el alargamiento de la temporada de estiaje. Es hasta que el hábitat, las costumbres, las actividades y los bienes se ven comprometidos por las afectaciones derivadas del meteoro, que se

${ }^{21}$ Velasco, "Importancia", 2006, p. 12. reconoce y se comienza a actuar en consecuencia, aunque en muchos casos ya pudiera ser tarde para revertir las secuelas, pues "es común la tendencia a menospreciar su presencia, esperando que sea algo de corta duración y sin mayores incidentes". ${ }^{22}$ Sin embargo, las sequías pueden colapsar e inutilizar la operatividad de los gobiernos y su infraestructura.

Las sequías son difíciles de detectar cuando están iniciando por el hecho de que los gobiernos y la sociedad confían en que sus necesidades de agua serán satisfechas por las reservas existentes en las presas (paradigma de la abundancia), por lo que no preocupa (en primera instancia) que las lluvias se retrasen o se interrumpan. La revisión de la prensa nos señala que desde 2009 se suscitaron los primeros brotes del último episodio de sequía que actualmente afecta al país y el cual, prácticamente, pasó inadvertido para la mayor parte de la sociedad y para el gobierno. Son muy pocas las notas que hacen referencia al fenómeno y aún más escasas las notas donde se mencionen acciones para combatirlo. Este silencio denota insensibilidad y una negación ante un hecho que poco a poco se tornaría un grave problema que aún perdura.

En agosto del año 2009 el subdelegado de la Secretaría de Agricultura y Ganadería Roberto Salinas, señalaba que en Tamaulipas había 7400 hectáreas dañadas por la sequía, pero también minimizaba sus efectos, mencionando que era "aún prematuro establecer un panorama 'catastrófico' ante la falta de lluvias". ${ }^{23}$ Respecto a la mortandad de 3000 cabezas

${ }^{22}$ Ibid., p. 12.

23 "Sequía en Tamaulipas daña 7400 hectáreas", Proceso, 28 de agosto 2009. 
de ganado que ya se contabilizaba, el mismo Salinas dijo que esa cifra "puede considerarse dentro del rango normal de mortandad que enfrentan cada año los productores, si se toma en cuenta que el hato ganadero de Tamaulipas es de más de un millón 400 mil animales". La positiva actitud del funcionario se basaba en que todo puede pasar, es decir: "Las lluvias pueden presentarse la próxima semana y cambiar totalmente el panorama." 24 Esta falta de sensibilidad del subsecretario Salinas contrasta significativamente con lo declarado por el director de la CONAGUA, José Luis Luege, en el año 2010, cuando señaló que una tercera parte del país tenía desabasto de agua debido al episodio de sequía que se estaba padeciendo a consecuencia del fenómeno del niño. ${ }^{25}$ Sin embargo, a pesar de semejante declaración, no se hace mención que se llevaron a cabo acciones drásticas encaminadas a combatir o al menos paliar los efectos de la sequía, sólo se limitó a señalar que ese desabasto sería tomado en cuenta en la administración de las presas. ${ }^{26}$

Un mes después, la prensa señalaba que miles de trabajadores rurales se encontraban en riesgo de quiebra si el gobierno no tomaba "medidas para amortiguar los efectos de las sequías para este 2010". ${ }^{27}$ También se mencionaba que los campesinos todavía no se reponían de los efectos de la sequía del año pasado y que ocasionó la pérdida de 700000 hectáreas en todo el país, por lo que reclamaban "mayor inver-

${ }^{24}$ Ibid.

25 Adriana Alatorre, “Advierte ConAGUA desabasto por sequía”, El Mañana, 5 de marzo de 2010. ${ }^{26}$ Ibid.

27 Julián Sánchez, "Demandan plan contra las sequías”, El Universal, 1 de abril de 2010. sión pública". ${ }^{28}$ Aunque el panorama se vislumbraba bastante trágico, la sequía dejó de ser cubierta por la prensa porque finalmente llegaron las lluvias y, de acuerdo con los diarios, el temporal fue generoso, ya que se terminó considerando a 2010 como "el año más lluvioso del que se tenga registro". 29

Pero aunque 2010 se haya catalogado como uno de los más lluviosos de la historia, el déficit de agua persistió. Parece que el gasto de agua realizado durante el tiempo en que duró la sequía durante 2009 y parte de 2010 fue mucho mayor de lo que pudo recargarse con las lluvias, por tanto, al presentarse un nuevo episodio de sequía en 2011 la escasez también se presentó y de forma más severa, ya que aparecen muchas notas periodísticas que hablan sobre la sequía (la nueva sequía) y sus efectos en México.

El Siglo de Torreón publicó una nota titulada "Suma la sequía nueve meses en México", en la que se establece que para junio de 2011 el pronóstico de precipitaciones indicaba que las lluvias estarían por debajo de lo normal en once estados del país. De igual forma, se menciona que algunos estados del país continuarían con un volumen de precipitación bajo a lo largo del mes de agosto. ${ }^{30}$ Ya para ese momento las autoridades federales consideraban este episodio de sequía como uno de los más intensos en 70 años, al tomar como referencia que mayo había sido

\footnotetext{
${ }^{28}$ Ibid.

${ }^{29}$ José Luis Caballero, "México, en el umbral de una sequía histórica", El Economista, 23 de enero de 2012.

${ }^{30}$ Agencia Reforma, "Suma la sequía nueve meses en México", El Siglo de Torreón, 15 de junio de 2011.
} 
el segundo mes más seco desde 1941. Esto dio a lugar a que en $44.8 \%$ del territorio se presentara la sequía y que se la catalogara "como extrema y excepcional". ${ }^{31}$

La situación por la sequía en 2011 comenzaba a tornarse más que complicada y las declaraciones hechas por los funcionarios gubernamentales y los meteorólogos así lo confirman. El secretario de la SEDESOL, Heriberto Félix Guerra, mencionó: "suman ya dos millones $500 \mathrm{mil}$ personas las que viven en mil 507 comunidades del país, quienes carecen de agua potable debido a la sequía". ${ }^{32}$ En ese mismo sentido, Gerardo Sánchez, líder de la Confederación Nacional Campesina (CNC), informó que "un total de 6 millones de hectáreas de cultivo resultarían siniestradas por la inusual sequía que afecta a 15 entidades del país". ${ }^{33}$ Por su parte, Martín Ibarra, miembro del Servicio Meteorológico Nacional (SMN), señaló que "las condiciones de sequía se iban a alargar", y agregó que por esta razón "va a ser difícil que con una temporada normal de lluvia se restablezca la humedad necesaria". ${ }^{34}$

El balance final que dejó la sequía en 2011 fue que afectó en diferentes grados a 19 de los 32 estados del país y siniestró 2700000 hectáreas de frijol y maíz. ${ }^{35}$

${ }^{31}$ Ibid.

${ }^{32}$ Cecilia Higuera, "2.5 millones de mexicanos, sin agua por sequía”, La Crónica, 29 de noviembre de 2011.

${ }^{33}$ Verónica Espinosa, "Pedirá CNC declarar zona de desastre en 15 entidades", Proceso, 20 de junio de 2011.

${ }^{34}$ Agencia Reforma, "Suma la sequía nueve meses en México”, El Siglo de Torreón, 15 de junio de 2011.

${ }^{35}$ José Luis Caballero, "México, en el umbral de una sequía histórica", El Economista, 23 de enero de 2012 .
Para 2012 los pronósticos no eran nada esperanzadores, ya que se señalaba que la sequía (sus efectos) se recrudecería en función de que el país sería afectado por la ausencia de alimentos y de agua en $68 \%$ del territorio. ${ }^{36}$ Sin embargo, pese a estos señalamientos, de nuevo las notas referentes a la sequía bajarían en cuanto a cantidad y espacio en los diarios, por lo que salen del imaginario colectivo al no ser consideradas noticias de gran relevancia, por lo que fue difícil seguir dándole un seguimiento puntual al fenómeno. Sería hasta que algo nuevo fungiera como un detonante mediático para que la prensa, el gobierno y la sociedad en su conjunto, fijaran otra vez su atención en la sequía y en sus efectos.

El evento que hizo que la prensa nuevamente centrara su atención en la sequía, fue el rumor de que 50 indígenas tarahumaras se habían suicidado ante la impotencia de no poder alimentar a sus hijos. ${ }^{37}$ El rumor fue confirmado en parte por el secretario del Ayuntamiento de Carichí, Chihuahua, Jesús Quiñones, quien hizo del conocimiento de los medios la gran hambruna que azotaba a la etnia tarahumara como consecuencia de la sequía, pero fue en las llamadas redes sociales (Facebook y Twitter) donde mayor impacto tuvo este rumor, ya que derivó en una convocatoria para recabar alimentos, agua y dinero para enviarlos a los rarámuris. ${ }^{38}$

De inmediato el gobierno salió a desmentir el supuesto suicidio. José Luis Luege

\footnotetext{
${ }^{36}$ Patricia Dávila, "El próximo año habrá sequías en $68 \%$ del país: CCC", Proceso, 20 de diciembre de 2011.

37 "Rumor de suicidio colectivo en la sierra Tarahumara hace fluir ayuda", Proceso, 17 de enero de 2012. ${ }^{38} \mathrm{Ibid}$.
} 
afirmó categóricamente que eran falsas las versiones sobre muertes de tarahumaras por falta de alimentos y agua, ${ }^{39}$ y aseveró que en la sierra Tarahumara la sequía no es severa como en otros lugares porque en este sitio existen fuentes de agua durante todo el año. ${ }^{40}$ Además, Luege sentenció que no iba a faltar el agua porque la iban a llevar "en pipas, en tanques especiales de 10 mil litros". ${ }^{41}$ Por su parte, Servando Portillo, secretario de Fomento Social de Chihuahua, mencionó, "con toda confiabilidad y certeza, que no hay suicidio colectivo". Porque el gobierno estatal estaba aplicando el programa denominado "Chihuahua vive" para llevar ayuda alimentaria a 22 municipios de la sierra Tarahumara, atendiendo a un total de 260000 habitantes. ${ }^{42}$ Por último, la coordinadora general de Protección Civil, Laura Gurza, dijo que no se tenían "reportes de ninguna especie alrededor de este tipo de actos de suicidios y mucho menos de orden masivo". 43

Haya sido verdad o no lo de los suicidios por hambre, lo positivo de este rumor es que permitió que comenzaran a llevarse a cabo acciones encaminadas a paliar los efectos de la sequía (principalmente que fluyera la ayuda hacia la sierra Tarahumara ${ }^{44}$

\footnotetext{
39 "Falso que tarahumaras hayan muerto de hambre y sed: Luege", La Jornada, 17 de enero de 2012.

${ }^{40}$ Notimex, "Luege niega sequía en la sierra Tarahumara", Excélsior, 16 de enero 2012.

${ }^{41}$ EFE, "Pese a sequía no faltará agua en la sierra Tarahumara", Centinela, 17 de enero de 2012.

42 "Grave sequía en Chihuahua; desmienten suicidios de tarahumaras", La Prensa, 17 de enero de 2012.

43 "Suicidios en la sierra Tarahumara: ¿verdad o rumor?", Adnpolítico.com, 18 de enero de 2012.

44 "Desata 'suicidio' colecta para Tarahumara", El Siglo de Torreón, 17 de enero de 2012.
}

y detonó un boom mediático que dio como resultado que la sociedad por completo se diera cuenta de la realidad que se vive en los estados del norte, es decir, finalmente se percibió y se aceptó, dentro del imaginario social, que México como país, como nación, estaba padeciendo el episodio de sequía más intenso registrado en los últimos 70 años.

El reconocimiento de la sequía y el de la escasez de agua dio lugar a que otros problemas derivados fueran traídos a la palestra mediática y, a su vez, permitió observar cuál era la realidad total de la situación, porque permitió valorar el grado de severidad y magnitud de los problemas; qué se hace para solventar la contingencia, y cuáles son los discursos que las autoridades manejan respecto a la sequía en diferentes momentos. Sobre este último punto, la evaluación de los discursos permitirá establecer si las acciones y políticas emprendidas por las autoridades fueron las correctas para enfrentar el problema o si, por el contrario, la contingencia rebasó al gobierno.

\section{LAS CONSECUENCIAS SOCIALES DE LA SEQUÍA Y LA ESCASEZ DE AGUA}

Uno de los problemas derivados de la sequía y de la escasez de agua que más se menciona en la prensa es el referente a las pérdidas que ha sufrido el agro durante los últimos tres años. De acuerdo con las cifras, las pérdidas alcanzan los 16000 millones de pesos (1 300 millones de dólares). De esta cantidad, 9000 millones corresponden a los cultivos perdidos de maíz y 6000 millones a los de frijol. Las pérdidas podrían seguir ascendiendo debido a que se estima que la sequía con- 
tinúe por lo menos hasta el verano de 2012. ${ }^{45}$

Los efectos inmediatos que dejan estas pérdidas se reflejan en el alza a los precios de la canasta básica; de acuerdo con el INEGI, de noviembre de 2006 a febrero de 2012 el aumento en los precios de los alimentos ha sido de $40.3 \%,{ }^{46}$ condición que hizo que la canasta básica se volviera "inalcanzable para millones de trabajadores", en función de que la canasta pasó de 805.34 pesos, a 1100 pesos, aumento "que no pueden cubrir trabajadores que perciben de uno a tres salarios mínimos". ${ }^{47}$ En ese mismo sentido, la empresa consultora Merrill Lynch señala que el alza en los productos básicos continuará debido a que tras una sequía la volatilidad permanece por alrededor de ocho meses, además, se prevé que la sequía persista porque "los pronósticos de lluvia no resultan muy optimistas". 48

La pérdida de las cosechas, a su vez, eleva el riesgo de padecer una hambruna generalizada por no poder garantizar el abasto de alimentos. El riesgo de la hambruna se debe a que de los 21000000 de hectáreas cultivables, 16000000 "dependen de los ciclos de lluvia, ya que no hay posibilidades de que puedan recibir agua de una manera distinta a la precipitación pluvial". ${ }^{49}$ La manera en que se trata de

45 "EU, cifra en 16 mil mdp., pérdidas por sequía”, El Universal, 5 de abril de 2012.

${ }^{46}$ Aura Hernández, "Los alimentos crecen el doble que inflación”, La Razón, 21 de marzo de 2012.

${ }^{47}$ Agencias, "Calculan pérdidas por sequía en 1300 millones de dólares", La Crónica, 5 de abril de 2012.

${ }^{48}$ Notimex, "Impactará sequía los precios agrícolas en México”, La Razón, 15 de marzo de 2012.

49 Roberto Arteaga, "Sequía en México quema los negocios en el campo”, El Financiero, 6 de marzo de 2012. evitar que se suscite una escasez de alimentos es mediante la importación de granos básicos, pero esto es una solución a medias, ya que a la larga el costo de la sistemática importación ocasionará que el campo mexicano deje de producir ${ }^{50}$ y esto obliga a los agricultores a migrar a las ciudades o incluso al extranjero. La Comisión de Asuntos Agrícolas, Frutícolas y Pecuarios de Durango mencionó que "80 000 campesinos han migrado debido a la falta de ingresos por la sequía que afectó al campo duranguense". De igual forma se menciona que en Múzquiz, Coahuila, la sequía ha propiciado que se incremente el número de migrantes a Estados Unidos por el hecho de que no hay fuentes de empleo. El desempleo es otro de los problemas atribuibles o derivado de un episodio de sequía, pues al perderse la siembra, se detiene la contratación para el trabajo agrícola de recolección. ${ }^{51}$ En lo que respecta al rubro de la ganadería, la prensa señala que por la sequía imperante en el país han muerto 1000000 de reses porque no hay pastizales para alimentarlas ni agua suficiente para que beban. ${ }^{52}$

También, por efecto de las sequías, parte de la infraestructura estratégica deja de ser funcional, como es el caso de las presas, que casi se vacían o de plano se han secado. La presa "La Rosilla II" se encuentra en $1 \%$ de su capacidad, y con este volumen de agua es imposible que

50 "Aumentará la importación de granos básicos por la sequía: CNC”, Punto por Punto, 24 de febrero de 2012.

${ }^{51}$ Manuel Quezada Barrón, "Presenta el estado la mayor tasa de desempleo", El Diario, 20 de abril de 2012.

52 "Sequía provoca muerte de un millón de reses", El Pueblo, 4 de mayo de 2012. 
pueda operar, por tanto, las zonas agrícolas y los asentamientos urbanos que dependen de ella deben ser abastecidos por medio de pipas. ${ }^{53}$ A principios del siglo XX, cuando se dio el boom de la construcción de las grandes presas, estas obras fueron consideradas como una solución a la sequía porque se suponía que serían capaces de almacenar una gran reserva para garantizar el abasto de agua durante los meses de estiaje y cuando un episodio de sequía se presentara, sin embargo, la mala administración de los embalses, aunada al largo periodo de sequía, dan lugar a que estas construcciones sean inoperantes.

Finalmente, la situación actual de sequía y de escasez ha comenzado a provocar tensiones y conflictos por el agua en diversas escalas y rubros; por ejemplo, en los estados del norte, donde más han sido afectados por la sequía, "ya comenzó la disputa por el agua entre comunidades rurales y urbanas". Mientras que los agricultores reclaman que se les está quitando el agua destinada al riego de sus cultivos para abastecer a las ciudades, los pobladores urbanos manifiestan que el agua destinada a las urbes se desvía para el riego de plantíos. De continuar la sequía y de no hacer nada para remediarla, los conflictos podrían agravarse y llegar a la violencia. ${ }^{54}$

Por todo lo ya mencionado, se revela que no estamos lo suficientemente preparados para afrontar una prolongada sequía, pues claramente se observa que la contingencia nos rebasa. La reacción del gobierno ante el problema ha sido demasiado lenta,

53 Corresponsales, "Crisis de agua en las presas del norte", El Universal, 13 de mayo de 2012.

${ }^{54}$ Matilde Pérez, "Campo y ciudades del norte pelean por agua", La Jornada, 18 de mayo de 2012, p. 37. y las acciones emprendidas no han sido las mejores. La revista Proceso menciona que fue un año después que el gobierno federal tomó en serio la petición de ayuda que exigían las organizaciones campesinas. La misma revista señala que la hambruna en la Tarahumara se pudo evitar, pero desde el inicio del sexenio (2006) se excluyó a los rarámuris del programa de atención prioritaria y del programa "Oportunidades". 55

\section{El MANEJO DE LA CONTINGENCIA}

A pesar de que los medios evidenciaron que el gobierno federal fue rebasado por la contingencia, los diferentes funcionarios han declarado que esto no es así. Laura Gurza, la coordinadora general de Protección Civil, señaló que el gobierno federal en ningún momento fue superado por la contingencia, al contrario, se respondió a tiempo. ${ }^{56}$ Similarmente, el presidente Felipe Calderón confirmó que estaba garantizado el abasto de agua y el alimento para todo el territorio nacional. ${ }^{57}$ En ese mismo sentido, José Luis Luege mencionó que todo estaba bajo control y que se supo manejar la situación con oportunidad, por tanto, era posible garantizar que no iba a faltar agua ni tampoco recursos económicos. ${ }^{58}$

\footnotetext{
${ }^{55}$ Marcela Turati, "Tarahumara: del presidente para abajo, la negligencia", Proceso, 4 de febrero de 2012.

${ }^{56}$ Carlos Quiroz, "Gobierno federal no está rebasado por sequía: SEGOB”, Excélsior, 17 de enero de 2012.

${ }^{57}$ Arturo Rodríguez, "Nos pusimos las pilas ante sequía: Calderón”, Proceso, 6 de febrero de 2012.

58 "A pesar de la sequía, todo está bajo control, según Luege Tamargo”, La Prensa, 6 de marzo de 2012.
} 
De todos estos discursos se desprenden las siguientes acciones encaminadas a sobrellevar los efectos de la sequía. La SEDESOl y la SEMARNAT pusieron en funcionamiento el "seguro catastrófico", una medida encaminada a proteger el patrimonio de agricultores y ganaderos. ${ }^{59}$ También se implementó el abastecimiento de agua a la población por medio de pipas $\mathrm{y}$ de tanques almacenadores, la repartición de 30000 paquetes alimentarios para 1222 familias ${ }^{60}$ y el envío de recursos para continuar con la perforación de pozos. ${ }^{61}$

El manejo del problema de la sequía por parte de las autoridades parece poco óptimo en comparación con la magnitud y la cantidad de problemas derivados del meteoro. Alfonso Larqué expresó su preocupación por la carencia de un banco de datos sobre la sequía que permita una mejor administración de los recursos y un mejor manejo de la situación. "Si las sequías son cíclicas, no es posible que a la fecha no haya un plan que atienda este tipo de circunstancias. Año tras año es la misma historia y sólo parchamos los problemas." ${ }^{62}$ La sequía, según el reportero Jaime Morales, es "un fenómeno asociado al cambio climático y también a un manejo inadecuado de los recursos naturales", es decir, parte de las secuelas de las sequías son producto de las pésimas políticas de

59 Notimex, "Presenta gobierno federal avance de acciones contra sequía", La Crónica, 9 de febrero de 2012.

${ }^{60}$ Víctor Manuel Chávez, "Arrecia Sedesol su lucha contra la sequía”, El Occidental, 15 de abril de 2012.

61 "Durango enfrenta la peor sequía de su historia", Nosotros Diario, 19 de abril de 2012.

${ }^{62}$ Natalia Gómez Quintero, "Enfrenta México sequía extraordinaria, alerta”, El Universal, 21 de enero de 2012. desarrollo del campo; "el país está cosechando los resultados de la ortodoxia neoliberal, inaugurada por los gobiernos priistas y continuada gustosamente por los panistas." La promoción de los cultivos de exportación, la importación de alimentos y la pérdida de la autosuficiencia alimentaria son aspectos que hacen más vulnerable al campo ante los efectos de una sequía. ${ }^{63}$

Jorge Galicia, otro reportero, considera que "algunos programas implementados no han avanzado al ritmo que la emergencia demanda"; ${ }^{64}$ esto se debe a varios aspectos, por ejemplo, no fue posible acceder a los 34000 millones que el gobierno federal autorizó para resolver las necesidades más inmediatas porque se trata de un monto proveniente de diversos programas, no de un fondo único. ${ }^{65}$ Además, existe descoordinación en las dependencias encargadas de hacer llegar la ayuda económica, la cual funge a modo de compensación porque no restituye al $100 \%$ las pérdidas. ${ }^{66}$ También, cuando se menciona que el abastecimiento de agua está garantizado, se refiere al uso doméstico, principalmente para beber, pero no para el riego ni para la ganadería. ${ }^{67}$

${ }^{63}$ Jaime Morales, "El hambre, la sequía y el campo en México", La Jornada Jalisco, 24 de enero de 2012.

${ }^{64}$ Jorge Galicia, "Sequía: lo peor está por venir", Sol de México, 11 de marzo de 2012.

${ }^{65}$ Matilde Pérez, "Tarahumaras y tepehuanos confían más en la ayuda divina que en la de instituciones", La Jornada, 24 de abril de 2012.

${ }^{66}$ Angélica Enciso, "Denuncian falta de apoyos por la sequía; sólo se entrega en contadas comunidades", La Jornada, 27 de febrero de 2012, p. 12.

${ }^{67}$ Matilde Pérez, "Campo y ciudades del norte pelean por agua”, La Jornada, 18 de mayo de 2012 , p. 37. 
En suma, las medidas implementadas por el gobierno son más paliativos que soluciones a los efectos de la sequía y la escasez, es decir, con las acciones llevadas a cabo se intenta soportar la contingencia hasta que llegue el temporal a ponerle fin, pero, de acuerdo con los especialistas, es posible que la sequía se extienda "dos o tres años más" ${ }^{68}$ Este escenario poco alentador agudizará la escasez de agua porque las presas siguen muy abatidas y los efectos de las sequías "son acumulativos y crónicos". 69

LA POLÍTICA DEL TRASVASE: ¿PARADIGMA FUNCIONAL O CADUCO?

Si el problema de la sequía en la actualidad se observa trágico, para el futuro las cosas se vislumbran todavía peor. César Nava establece que en los últimos 30 años la disponibilidad de agua per cápita ha ido disminuyendo $y$, de mantenerse esa tendencia, en el año 2025,

algunas regiones alcanzarán niveles cercanos e incluso inferiores a los $1000 \mathrm{~m}^{3} / \mathrm{hab} / \mathrm{año}$, lo que es considerado dentro de la escala de clasificación como una disponibilidad "muy baja" o "extremadamente baja", respectivamente. ${ }^{70}$

Las estimaciones de los expertos indican que el reto a futuro es poder abastecer las demandas de agua de las grandes ciudades por el hecho de que hoy en día

\footnotetext{
68 "La sequía en México podría extenderse hasta tres años más”, Sol de México, 15 de febrero de 2012

69 "Alerta en México por sequía”, Vanguardia, 21 de enero de 2012.

${ }^{70}$ Nava, "Agua”, 2008, p. 63
}

muchas de ellas ya tienen un acentuado déficit hídrico, como es el caso de la ciudad de México, urbe que a lo largo de su historia ha padecido constantes episodios de escasez pues, por su acelerado crecimiento demográfico, ha sido incapaz de satisfacer las necesidades de agua de la población con sus propios recursos, por lo que en varios momentos ha sido necesario buscar nuevas fuentes de agua con que abastecerla.

La relación que guarda la ciudad de México con el agua es contradictoria, pues en un principio la necesidad imperante fue la desecación de los lagos de la cuenca para evitar las inundaciones, ${ }^{71}$ posteriormente se comenzó a realizar lo opuesto: buscar agua para abastecer a la ciudad. Antes de 1950 la ciudad de México se abastecía totalmente de los acuíferos subterráneos, pero debido a que la ciudad comenzó a presentar hundimientos a consecuencia de la extracción, se consideró necesario ubicar nuevas fuentes con que complementar el abasto. ${ }^{72}$ Es así como se desarrolla la primera obra de trasvase de agua de una cuenca aledaña a la ciudad de México, sin embargo, dos décadas después el caudal transferido de la cuenca del Lerma fue considerado insuficiente para sostener las demandas de la metrópoli, así que se comenzó a buscar una nueva fuente de dónde importar agua. ${ }^{73}$

En 1972 la entonces Secretaría de Recursos Hidráulicos presentó un estudio donde se evaluaban las alternativas para "solucionar la problemática de abasteci-

\footnotetext{
${ }^{71}$ González, "México", 1955, pp. 506-522.

${ }^{72}$ De los acuíferos se extraen $1876 \mathrm{hm}^{3}$, mientras que se recarga un volumen de $883 \mathrm{hm}^{3}$ por año. Breña y Breña, "Problemática”, 2009, pp. 10-18.

73 Perló y González, “Agua”, 2006, pp. 47-65.
} 
miento de agua". ${ }^{74}$ De nueva cuenta se consideró el trasvase de agua desde otra cuenca como la solución más viable, y se pensó que dicho plan cubriría la demanda de líquido hasta el año 2000. En 1982 se inauguró el sistema Cutzamala, "uno de los sistemas de suministro de agua potable más grandes del mundo, no sólo por la cantidad de agua que transporta

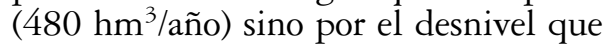
vence (1 $100 \mathrm{~m})$ ". . $^{75}$

Resulta evidente que la política del trasvase no ha sido suficiente para solucionar los problemas de escasez de una ciudad tan grande como la ciudad de México, por el contrario, es necesario buscar una nueva fuente de agua; sin embargo, cuando se realiza un trasvase las cuencas donantes muestran sobreexplotación y deterioro ambiental, es decir, por la extracción indiscriminada se está perdiendo la fertilidad de los suelos de la cuenca donante y con ello se modifica el paisaje, la forma de vida y la economía de los habitantes de las cuencas de donde se transfiere agua a la capital. ${ }^{76}$

La ConAgua señala que el deterioro de las cuencas donantes y las sequías ponen en riesgo de crisis a la ciudad de México por una eventual escasez de agua. José Luis Luege informó que la ciudad de México está al borde del colapso por falta de agua. ${ }^{77}$ Esta situación puede presentarse en el mediano plazo, esto porque durante 2011 las reservas de agua del Cutzamala disminuyeron $100 \mathrm{~mm}^{3}$, "y aunque está garantizado el abasto del

${ }^{74}$ Corona, "Trasvase", 2010, pp. 1-24.

75 Perló y González, "Agua”, 2006, p. 55.

${ }^{76}$ Kloster y Alba, “Agua”, 2007, pp. 137-159.

${ }^{77}$ Notimex, "Urge rescatar barrancas y ríos para evitar escasez de agua", Milenio, 8 de mayo de 2012. líquido para el primer semestre de 2012, en caso de que la lluvia sea escasa en 2013 se podría vivir una emergencia por falta de agua en la capital". ${ }^{78}$

De acuerdo con las proyecciones, la demanda de agua continuará en ascenso, puesto que se prevé que para 2040 la población aumente hasta 123000000 en todo el país. ${ }^{79}$ Pero también se menciona que las fuentes de agua cada día se verán más reducidas, entonces, surge la siguiente interrogante: ¿de dónde se sacará el agua suficiente para abastecer a toda la población? Sin agua no hay futuro, por tanto, es necesario tomar muy en serio las alertas que indican que en gran parte del país (sobre todo en las grandes ciudades) existe el problema de la escasez de agua y comenzar a buscar una solución diferente al sistema de trasvase pues, en mi opinión, este sistema ya no es una opción viable, por el hecho de que el agua en todas las cuencas es y se prevé que sea más escasa, por lo tanto, la importación de una cuenca a otra implicará tensiones y conflictos.

\section{LA SEQUÍA Y LA ESCASEZ DE AGUA: PERSPECTIVAS FUTURAS}

¿Qué es lo que se puede hacer para solucionar la problemática de la escasez de agua que se cierne en los próximos años?, ¿existe alguna opción viable y diferente al trasvase que evite el colapso de nuestras ciudades y de nuestra sociedad? En este caso conviene hacer uso de la historia

\footnotetext{
${ }^{78}$ MCA, "D. F., podría vivir emergencia por falta de agua en 2012: SACM", Excélsior, 26 de enero de 2012.

79 Pineda, Salazar y Buenfil, “Dar”, 2010, pp. $117-140$
} 
para revisar experiencias similares, estudiar las soluciones que se implementaron y que resultaron exitosas para corregir sus fallas y mejorar los resultados. En ese sentido, considero que un vistazo a la experiencia de los países del Medio Oriente podría ilustrarnos sobre nuevas alternativas para enfrentar las sequías y los problemas de escasez de agua en función de que, en estas naciones, estos problemas y los conflictos derivados de estos fenómenos han sido aspectos comunes de la vida diaria de estas sociedades a lo largo de su historia. De igual forma, creo que existen algunas similitudes entre nuestro país y los pueblos del Medio Oriente que posibilitan la viabilidad de aplicar las mismas soluciones que se han llevado a cabo en algunos de estos países para contrarrestar los efectos de las sequías y la escasez de agua.

La zona del Medio Oriente ha sido considerada por los países occidentales como una zona estratégica porque a principios del siglo XX se descubrió la existencia de grandes yacimientos petrolíferos, pero también es considerada una zona altamente conflictiva por aspectos nacionalistas, políticos, religiosos y también por la disputa del agua, un recurso sumamente escaso en estas latitudes. ${ }^{80}$ Desde 1980 el servicio de inteligencia de Estados Unidos estima que existen al menos diez lugares en esta zona donde la guerra por agua se podría suscitar. ${ }^{81}$ Se establece que el agua es motivo de conflicto en el Medio Oriente porque esta zona del mundo es una zona desértica con bajos índices de precipitación pluvial al año, por lo tanto, el acceso a las fuentes de agua es, desde la

\footnotetext{
${ }^{80}$ Selby, "Geopolitics", 2005, pp. 329-349.

${ }^{81}$ Starr, "Water", 1991, pp. 17-36.
}

década de los años sesenta, causa de disputa y conflicto internacional. ${ }^{82} \mathrm{El}$ problema del agua en esta zona se ha intensificado en los últimos años, de hecho se estimaba que de no hacer algo para revertir la situación, para el año 2050 las reservas de algunos países del Medio Oriente colapsarían totalmente. $^{83}$

\section{LA EXPERIENCIA DESALINIZADORA SAUDITA; UN EJEMPLO A SEGUIR}

La desalinización es una tecnología que ha ayudado a disipar las tensiones políticas en el Medio Oriente y también ha permitido que algunas sociedades logren despuntar, como en el caso de Arabia Saudita, país que en la actualidad ostenta el primer lugar en desalinización de agua de mar. ${ }^{84}$ Arabia Saudita es uno de los países más grandes del Medio Oriente, su extensión territorial cubre un área de $2253000 \mathrm{~km}^{2}$, y por sus condiciones climáticas también es considerado como uno de los más áridos del mundo. ${ }^{85}$ Arabia recibe, en promedio, $100 \mathrm{~mm}$ de lluvia al año, nivel considerado muy bajo, por lo que es común que por años no llueva, además, carece totalmente de ríos superficiales. ${ }^{86}$

\footnotetext{
${ }^{82}$ El triunfo en la "guerra de los seis días" le dio a Israel un acceso y control importante sobre las aguas del río Jordán y los acuíferos de Cisjordania. Knighton, "Thirsty", 2002, pp. 13-14.

${ }^{83}$ Chenoweth y Wehrmeyer, "Scenario", 2006, pp. $245-261$

${ }^{84}$ En la actualidad Arabia Saudita desaliniza 24000000 de metros cúbicos $\left(\mathrm{m}^{3}\right)$ de agua de mar al día. Lee, "Saudi", 2010.

${ }^{85}$ Raphael y Shaibi, “Water”, 1984, pp. 183-191.

${ }^{86}$ Hussain et al., "Revitalizing", 2008, pp. 333-349.
} 
Por lo ya dicho, Arabia Saudita carecía de industria y su economía se basaba en el pastoreo nómada y en la agricultura artesanal concentrada en los oasis existentes. En el aspecto demográfico, Arabia contaba en el año de 1930 con cerca de dos millones de habitantes, sin embargo, a partir del año 1960 se suscita el rápido despunte industrial, agrícola, urbano y demográfico, y esto se dio gracias al descubrimiento y posterior explotación de los yacimientos petrolíferos. ${ }^{87}$ Fue bajo el mandato del rey Faisal cuando se suscita el desarrollo saudita que le permitió abandonar su forma tradicional de vida y esto se logró gracias a que los sauditas utilizaron los activos obtenidos del petróleo para reinvertirlos en la construcción de la infraestructura necesaria para modernizar el país, enfocándose principalmente en atender el problema de la escasez de agua. ${ }^{88}$

Por las escasas lluvias y por la aridez del país, el poder abastecer de agua a la población era un problema de seguridad nacional, de ahí que no se escatimaran gastos para hacer lo que fuera necesario para resolver el problema, y es aquí cuando los sauditas consideraron viable emplear la desalinización como una alternativa capaz de solucionar sus problemas de agua, lo que a su vez les permitió desarrollarse y crecer a escala industrial y agrícola, así como demográficamente.

Bajo los auspicios del ministerio de Aguas y Agricultura Saudita comenzaron a llevarse a cabo los estudios necesarios para evaluar la disponibilidad de agua de cada una de las regiones del país para así determinar, estratégicamente, dónde y

${ }^{87}$ Beaumont, "Water", 1977, pp. 42-60.

${ }^{88}$ Ibid., p. 42. cuántas plantas desalinizadoras debían construirse para abastecer a la población, la agricultura y la industria. La información recabada dio como resultado el ambicioso y costoso programa de desalinización saudita, que implicaba construir un extenso número de plantas de diversos tamaños a lo largo de las costas del mar Rojo y del golfo Pérsico. Dicho programa contaba con objetivos a corto y a largo plazos: a corto plazo, el programa se enfocaba en abastecer de agua a las zonas que experimentaban la escasez más extrema. A largo plazo, el plan pretendía abastecer de agua de forma intensiva la mayor parte del territorio. Este objetivo implicó construir una serie de obras complementarias; plantas eléctricas, red de ductos y plantas de bombeo, con lo cual ha sido posible abastecer zonas y ciudades en el interior del país, como es el caso de Riad, actualmente la ciudad más grande y que a mediados de 1970 (gracias a que contaba con el suficiente abasto de agua) se convirtió en la capital del país. ${ }^{89}$

En efecto, de acuerdo con Elie Elhadj, los mayores centros urbanos, políticos y religiosos de Arabia Saudita, como Medina, Riad y la Meca, son abastecidos por medio de una red de ductos de $4160 \mathrm{~km}$ de longitud y que permiten distribuir agua desde las costas a todas las zonas del país; por ejemplo, la capital Riad, es abastecida por la planta desalinizadora de Jubail, ubicada en el golfo Pérsico, por medio de dos ductos que cruzan el desierto a lo largo de 450 kilómetros. Desde la ciudad de Riad se bombea agua por otro ducto hacia Buraida en el noroccidente, a 350 kilómetros de distancia y con ductos subsi-

\footnotetext{
${ }^{89}$ La demanda de agua pasó de 40 litros por persona por día a más de 500. Ibid., p. 54.
} 
diarios se conecta y se surte a diversos pueblos y villas en Najd Plateau. ${ }^{90}$

Por supuesto que llevar a cabo todo este proyecto ha sido muy oneroso, sin embargo, la imperante necesidad de agua llevó a los sauditas a obtenerla sin importar el costo, pues se consideraba que estaba en juego el futuro de Arabia, además, en la actualidad, las nuevas tecnologías han reducido los costos de operación de las desalinizadoras y hacen que esta alternativa sea competitiva con el agua dulce. ${ }^{91}$ En conclusión, la experiencia saudita es un claro ejemplo de que en la actualidad existen soluciones viables para contrarrestar exitosamente las sequías y la escasez de agua.

\section{LA DESALINIZACIÓN ¿OPCIÓN PARA MÉXICO?}

Para los sauditas la desalinización fue y ha sido una solución efectiva para sus problemas de agua que les permitió crecer y desarrollarse demográfica y económicamente. Asimismo, parece que su experiencia se ha convertido en un ejemplo a seguir, pues de acuerdo con la bibliografía especializada y los expertos, la desalinización se encamina a convertirse en la opción más viable para combatir la falta de agua, es decir, la desalinización se está estableciendo como en el paradigma a seguir. Según José Antonio Medina, ex presidente de International Desalination Association, para el año 2015 se desalinizarán 97000000 de $\mathrm{m}^{3}$ por día en el mundo. ${ }^{92}$

${ }^{90}$ Elhadj, "Household", 2004, pp. 1-22.

${ }^{91} \mathrm{El} \mathrm{m}^{3}$ de agua desalinizada tiene un costo de entre 40 y 90 centavos de dólar. Lee, "Saudi”, 2010

92 "Participa UNAM en el desarrollo de desaladoras”, El Informador, 4 de marzo 2012.
Este dato indica que la desalinización es una tecnología cada vez más utilizada, sobre todo porque diversas circunstancias se conjugan: en primer lugar, la demanda de agua aumentará exponencialmente, mientras que las reservas de agua dulce comenzarán a colapsar. ${ }^{93}$ Segundo, los precios de la desalinización siguen decreciendo y la eficacia tecnológica de los métodos y los procesos desalinizadores sigue incrementándose. ${ }^{94}$ En la actualidad la desalinización es una opción viable, tecnológica y económicamente hablando, para enfrentar la falta de agua y, en mi opinión, México cuenta con un gran potencial para llevar a cabo este proceso a gran escala, ya que tiene costas en el $\mathrm{Pa}$ cífico y en el Atlántico que alcanzan los 11000 kilómetros. ${ }^{95}$ El hecho de contar con tan vasta extensión de costera hace pensar en la posibilidad de desarrollar un corredor hídrico, instalando un gran número de plantas desalinizadoras en el Pacífico y en el Atlántico con las cuales se abastezca por medio de ductos a todos los estados y ciudades que hoy en día padecen sequía o déficit de agua. ${ }^{96}$

\footnotetext{
${ }^{93}$ El aumento de la población, el crecimiento agrícola e industrial y el cambio climático, son las causas que pondrán en situación crítica las reservas de agua, pues se proyecta que para el 2025 la demanda excederá en $56 \%$ la oferta actual. Clayton, Desalination, 2011, pp. 1-33.

${ }^{94} \mathrm{La}$ ósmosis inversa es el método desalinizador más empleado en el mundo, porque requiere de menor gasto energético y aún no llega a su techo tecnológico, por lo que el costo seguirá disminuyendo. Dziegielewski, "Role", 1999, pp. 395-398. Véase también, Zarza, "Desalinización”, 1997, pp. 199-226.

95 Jiménez et al., “Agua”, 2004, p. 11.

96 Actualmente en México ya operan alrededor de 300 plantas desalinizadoras a pequeña escala en
} 
A primera vista esta idea pudiera parecer inviable, sin embargo, en México ya existe un gran proyecto hidráulico similar en cuanto a reto tecnológico y costos, y me refiero al sistema Cutzamala, una obra hidráulica que surte a la ciudad de México desde 320 kilómetros de distancia y que vence un desnivel de 1100 metros. La necesidad de dotar de agua a la ciudad de México ha obligado a las autoridades a ir tan lejos como fuera necesario para obtenerla y a emplear y mover los recursos económicos, políticos, humanos, técnicos, tecnológicos y operativos necesarios para conseguirla. Claudia Corona dice que ante la emergencia por la falta de agua, el análisis costo-beneficio siempre apunta hacia el mismo resultado: "a pesar de la gran inversión económica que implicó la construcción de esta mega obra", hubiese sido más costoso dejar a la capital del país sin agua, porque en ella residen los poderes de la Unión, es el centro neurálgico de la política y del gobierno, es la esencia de la cultura nacional y el motor del país. ${ }^{97}$

Considero que la desalinización también podría ser implementada en la propia ciudad de México. Pensemos en el hipotético caso de que las fuentes actuales que abastecen a la ciudad ya no fueran suficientes para dotar de agua a la población. ¿Cuáles serían las acciones a tomar?, ¿se buscaría realizar un nuevo trasvase aunque esto implicara afectar a otras comunidades y desatara conflictos ecológicos, sociales y económicos?, ¿de qué otra cuenca se obtendría el agua suficiente para abastecer las demandas de la ciudad de México?, o simplemente, ¿los capitalinos

hoteles cercanos al mar. "Participa UNAM en el desarrollo de desaladoras", El Informador, 4 de marzo 2012.

${ }^{97}$ Corona, "Trasvase", 2010, p. 5. deberán de empacar sus cosas y abandonar la ciudad?

Por supuesto que abandonar la ciudad no es opción y tampoco lo es el trasvase, ya que en poco tiempo sería necesario buscar una nueva fuente de abastecimiento, entonces, parece que la última frontera que queda por explorar es el mar. A lo que me refiero es que la ciudad de México podría implementar un proyecto desalinizador similar al desarrollado en la capital saudita, es decir, se podría construir un complejo desalinizador en el Golfo y de ahí bombear agua desalinizada hacia la ciudad de México. De llevar a cabo un proyecto de este tipo, se podrían solucionar los problemas de agua no sólo de la ciudad de México, sino de otras regiones, pues la capital, al contar con su propia fuente de agua, ya no tendría que importarla de otras cuencas.

De igual forma, considero factible la idea de construir una serie de plantas desalinizadoras a lo largo de las costas del Golfo y del Pacífico para abastecer por medio de ductos a los estados y ciudades del norte del país y, con ello, solucionar la falta de agua de estas poblaciones que históricamente han padecido los efectos de las sequías y la escasez de agua y así, dejar de ser dependientes de los ciclos de lluvia, pues una de las ventajas de la desalinización, es que siempre se tendrá agua, llueva o no llueva.

Ahora bien, si la desalinización es el futuro ¿qué hace falta para llevarla a cabo?, ¿acaso carecemos de los conocimientos para implementarla?, ¿falta la experiencia técnica, tecnológica y operativa?, ¿los recursos económicos?, ¿falta voluntad política para emprender obras de este tipo? Creo que nuestro país tiene los conocimientos y la capacidad tecnológica y 
económica para poder construir un corredor hídrico a lo largo de las costas del país, por ejemplo, la Comisión Federal de Electricidad, en su página de internet, menciona que cuenta con el personal para realizar estudios técnicos "para el abastecimiento de agua”, además de consultoría para el diseño y desarrollo de infraestructura. ${ }^{98}$ Con los conocimientos que posee la CFE se ubicarían los sitios más idóneos donde construir las desalinizadoras, trazar la red de ductos y localizar los sitios de descarga del agua desalinizada.

Asimismo, en el portal de Pemex se señala que la paraestatal cuenta con $12764 \mathrm{~km}$ de ductos por donde se transportan diariamente un promedio de 5100 millones de pies cúbicos de gas natural. ${ }^{99}$ Estos datos nos indican que Pemex cuenta con la capacidad tecnológica para construir y operar una red de ductos y, asimismo, cuenta con la experiencia necesaria para mover líquidos por esta red de tubería, condiciones indispensables que pudieran ser utilizadas para poder llevar agua desalinizada de las costas hacia las ciudades y estados del interior del país.

También, para emprender un proyecto desalinizador de gran escala, es necesario contar con amplios recursos económicos, y hoy en día las reservas internacionales del país alcanzan la cifra de 153787 millones de dólares, ${ }^{100}$ cantidad más que

\footnotetext{
${ }^{98}$ Comisión Federal de Electricidad, <http:// www.cfe.gob.mx/QuienesSomos/estudiosdeingenieria/ Paginas/Estudiosdeingenieriacivil.aspx $>$. [Consulta: 30 de mayo de 2012.]

99 PEMEX, <http://www.gas.pemex.com/PGPB/ Conozca + Pemex + Gas/Infraestructura/Sectores $+\mathrm{de}+$ ductos/>. [Consulta: 30 de mayo de 2012.]

100 "Reservas internacionales caen por tercera semana consecutiva", El Economista, 22 de mayo de 2012.
}

suficiente para poder construir varias plantas desalinizadoras capaces de producir hasta $100 \mathrm{~mm}^{3}$ por año; ${ }^{101}$ es más, pensando de manera contrafactual, con el monto dispuesto por el gobierno federal para combatir la sequía (34000 millones de pesos) se podrían construir cinco plantas con capacidad para desalinizar $500 \mathrm{~mm}^{3}$ por año, volumen de agua que (contrafactualmente), sería un gran complemento para dar un mejor manejo a las presas, pues en la actualidad el agua existente en los embalses se reparte entre las ciudades y el campo. Pero si las ciudades contaran con un abastecimiento propio, toda el agua de las presas se canalizaría a la agricultura y con ello se evitarían las millonarias pérdidas económicas y los daños sociales derivados de la escasez de líquido. ${ }^{102}$

Siguiendo con los números, comparativamente el $\mathrm{m}^{3}$ de agua desalinizada es competitivo con el precio del agua dulce, pues mientras los costos de la desalinización siguen decreciendo, por la escasez los costos del agua dulce siguen incrementándose. $\mathrm{El} \mathrm{m}^{3}$ de agua desalinizada oscila los 90 centavos de dólar (alrededor de diez pesos) ${ }^{103}$ pero a esta cantidad se le debe sumar el costo de transportación, que se estima en cinco centavos por $\mathrm{m}^{3}$ por cada

${ }^{101}$ Israel ha invertido 423000000 de dólares (alrededor de 6000 millones de pesos) para construir una planta desalinizadora que proporcionará un tercio del agua que consumirá la población a partir del 2013. Ari Rabinovitchi, "Israel to build 423 millon desalination plant", Reuters, 8 de agosto de 2011.

${ }^{102}$ La desalinización es rentable cuando se destina al abastecimiento de las ciudades porque estas cuentan con la infraestructura necesaria para distribuirla al público mediante el pago de cuota.

${ }^{103}$ Lee, "Saudi", 2010, p. 1. 
100 kilómetros. Yuan Zhou y Richard $\mathrm{Tol}^{104}$ calculan que el costo de transportación del $\mathrm{m}^{3}$ para la ciudad de México sería de 2.40 dólares (considerando la elevación de 2500 metros), es decir, el costo total del $\mathrm{m}^{3}$ de agua desalinizada transportada desde la costa del Golfo hasta la ciudad de México oscilaría alrededor de los 30 pesos.

Pudiera parecer muy oneroso el $\mathrm{m}^{3}$ de agua desalinizada, sin embargo, de acuerdo con Ramón Aguirre, titular del Sistema de Aguas de la ciudad de México, "el costo por metro cúbico de agua en la capital del país es de 23 pesos, unos 1.81 dólares". ${ }^{105}$ El precio por $\mathrm{m}^{3}$ de agua dulce en la ciudad de México es muy cercano al estimado para el agua desalinizada, sin embargo, la tarifa para los usuarios es de cuatro pesos $/ \mathrm{m}^{3}$, lo cual indica que hay un subsidio al público de por lo menos 19 pesos. Si esa misma cantidad se destinara para subsidiar el agua desalinizada, el costo se reduciría a once pesos $/ \mathrm{m}^{3}$, una tarifa competitiva, considerando que en ciudades como Quintana Roo el costo por $\mathrm{m}^{3}$ de agua dulce está por arriba de los 30 pesos en la zona hotelera y quince pesos en áreas habitacionales, ${ }^{106}$ en Querétaro 19 pesos, ${ }^{107}$ o en Morelia 16.59 pesos. ${ }^{108}$

${ }^{104}$ Zhou y Tol, "Evaluating”, 2005, pp. 1-16.

${ }^{105}$ En Alemania el costo por metro cúbico es de 3.01 dólares, en Reino Unido de 2.37 dólares y en Francia de dos dólares. Jenaro Villamil, "Agua: oro por metro cúbico. Cuidarla para bien de todos. Contaminación, enemiga a vencer", El Diario de Coabuila, 4 de octubre de 2010.

106 "Se debe valorar el costo del agua potable", Peninsular Digital.com, 8 de febrero de 2012.

107 Abel de la Garza, "Aquí el agua más cara”, Diario de Querétaro, 31 de agosto de 2010.

108 "Precio del agua, a mitad del costo", El Informador, 22 de marzo de 2012.
Con el subsidio ${ }^{109}$ el menor costo del agua desalinizada puede ser una realidad tangible, además, resultan más costosos los daños por carecer de ella, no sólo por lo que se pierde, sino por lo que impide ganar, pues la falta de agua ha imposibilitado históricamente el crecimiento de algunas zonas del país por encontrarse inmersas en la eterna escasez del líquido. Por otra parte, ante la necesidad la gente no se negaría a pagar once pesos por un $\mathrm{m}^{3}$ de agua desalinizada, de hecho, la gente accede a pagar hasta diez pesos por un solo litro de agua embotellada, lo que equivale a pagar 10000 pesos por un metro cúbico. ${ }^{110}$

\section{EL PROBLEMA DE LA FRAGMENTACIÓN POLÍTICA DEL ESTADO}

Hasta este punto suena razonable, en cuanto a costos, conocimientos y experiencia técnica, que la desalinización a gran escala puede ser una opción viable para nuestro país. Ahora bien ¿el factor político permite la implementación y desarrollo de la desalinización? Al parecer es el entorno político el que impide que se lleve a cabo la desalinización a gran escala, pues para los gobernantes la opción más viable (más no definitiva) sigue siendo el trasvase de agua entre cuencas.

El trasvase entre cuencas continúa como el paradigma reinante entre los polí-

\footnotetext{
109 "Subsidio a gasolina para 2012 se agotó en primer trimestre”, El Informador, 2 de mayo de 2012. Véase también, Gabriel Quadri, "Electricidad y subsidios: ¿qué hacer?", El Economista, 3 de marzo de 2010.

${ }^{110}$ Leticia Gasca, "Hasta 90\% del costo del agua embotellada se debe a la botella", El Economista, 7 de julio de 2009.
} 
ticos mexicanos, sin embargo, como ya se ha mencionado, este sistema desata conflictos y no ofrece una solución definitiva. En la actualidad están en proceso de desarrollo dos obras hidráulicas de gran magnitud (una en Sonora y otra en Monterrey) cuyo rasgo común es la importación de agua para abastecer a dos grandes ciudades (Hermosillo y Monterrey), aunque ello implique negar y despojar del acceso al agua a otras personas, ciudades y regiones.

Uno de esos proyectos es el denominado "Monterrey VI", obra que busca garantizar el abasto de agua a la capital de Nuevo León por los próximos 50 años. En palabras del gobernador del estado, Rodrigo Medina, de no llevar a cabo este proyecto, el suministro para Monterrey se vería comprometido en un par de años. ${ }^{11}$ Este plan consistía, en un principio, en hacer un trasvase de 15000000 de metros cúbicos por año del río Tampaón, sin embargo, ante la protesta de las autoridades del vecino estado de San Luis Potosí (a quien afectaría la obra de trasvase) se tuvo que modificar el proyecto. ${ }^{112}$

Luego de hacer algunas modificaciones y de entablar negociones con el gobierno de este estado, se logró continuar con el desarrollo de la obra, ya que ambas partes encontraron un punto de acuerdo. Se decidió desplazar la toma de agua originalmente situada

en el cauce del río Tampaón, a una zona conocida como "Las Adjuntas", sobre la corriente del río Pánuco, cuyo flujo esti-

${ }^{111}$ Luis García, "Nuevo León busca financiar proyecto Monterrey VI", Milenio, 15 de agosto de 2011.

${ }^{112}$ Luis García, "Con modificaciones, realizarán proyecto Monterrey VI", Milenio, 21 de marzo de 2012 mado es 442 metros cúbicos por segundo, capaz de suministrar agua prácticamente a todo el país. ${ }^{113}$

En ese mismo sentido, el secretario de Desarrollo Sustentable de Nuevo León, Fernando Gutiérrez, mencionó que la obra Monterrey VI es un proyecto "a la vez sostenible y sustentable", porque la cuenca del Pánuco es de las pocas que no padece problemas de sobreexplotación ni está deteriorada como otras, por lo que permitirá a Nuevo León "enfrentar los problemas de planeación de su futuro sin lastres o limitaciones como la escasez de agua". ${ }^{114}$

Sin embargo, existen algunos señalamientos sobre este proyecto pues se considera que fue la opción más costosa y menos funcional de las ocho propuestas analizadas, ya que requerirá de 16000 millones de pesos para llevarse a cabo. Lo oneroso de la obra compromete las finanzas del estado durante los próximos 30 años; esta deuda la pagarán los usuarios (costos de operación y mantenimiento) a través de los incrementos a las tarifas del cobro del servicio, por lo que se concluye que la obra representa más un negocio que una solución al problema de la escasez de agua. $^{115}$

También se consideró llevar a cabo un proyecto desalinizador que en cuanto a costos se comparaba con el proyecto Monterrey VI (15 180 millones) y que planteaba construir 24 plantas desalinizadoras por ósmosis inversa y un acue-

\footnotetext{
${ }^{113}$ Luis García, "Logran trato NL., y SLP: Monterrey VI sigue en pie”, Milenio, 22 de marzo de 2012.

${ }^{114}$ Luis García, "Nuevo León busca financiar proyecto Monterrey VI", Milenio, 15 de agosto de 2011.

115 César Cepeda, "Monterrey VI: el negocio del sexenio”, Reporte Indigo, 24 de mayo de 2012.
} 
ducto de 310 kilómetros entre Monterrey y Matamoros para abastecer a las plantas con agua del Golfo. Sin embargo, las autoridades de Nuevo León optaron por un trasvase costoso que tan sólo garantiza el abasto de agua por 50 años ¿y después qué?, ¿de dónde se sacará el agua para abastecer a Monterrey?, ¿en 50 años ya se considerará viable la desalinización?, ¿por qué no ahora?

Los trasvases dejan más dudas que respuestas y también desatan muchos problemas económicos, políticos, sociales y ecológicos, puesto que un trasvase reconfigura el mapa geopolítico e hidrológico. Un trasvase provoca deterioro y desequilibrio interregionales, ya que la zona donante pierde sus posibilidades de crecimiento y desarrollo al ceder su acceso al agua a un centro urbano de mayor tamaño. ${ }^{116}$ Además, en la actualidad resulta difícil que se realice un trasvase sin conflictos debido a que desde los años ochenta el Estado ha padecido una fragmentación política que rompió la hegemonía gobernante del PRI, lo que a su vez debilitó su ejercicio totalitario del poder. ${ }^{117}$

Antes de 1980 el PRI gobernaba en todos los ámbitos (federal, estatal y municipal), por lo cual fue posible llevar a cabo, sin discusión, la creación del sistema Cutzamala; sin embargo, con la fragmentación política han surgido nuevos actores que se disputan el poder, así como los recursos naturales (su acceso); la cuarta fase del sistema Cutzamala, programada para 1997 y consistente en trasvasar agua de la cuenca de Temascaltepec, no se pudo llevar a cabo debido a las protestas de los habitantes de la zona.

116 Corona, “Trasvase”, 2010, p. 19.

${ }^{117}$ Kloster y Alba, “Agua”, 2007, pp. 139-147.
Algo muy similar acontece en Sonora desde que se dio a conocer el proyecto "Acueducto Independencia", una obra que pretende abastecer a la ciudad de Hermosillo trasvasando agua del Valle del Yaqui, aunque en un principio se proyectaba construir una desalinizadora para solucionar esta problemática, pero el plan se canceló "luego de que el Partido Acción Nacional mostrara su rechazo". ${ }^{118}$ Sobre la propuesta de trasvasar agua de la presa El Novillo, el diputado Faustino Félix manifestó que "nunca debe taparse un hoyo haciendo otro", puesto que tanto el Valle del Yaqui como Hermosillo podrían quedarse sin agua, además, en cuanto a costos, trasvasar agua es muy similar a la desalinizadora, la diferencia estriba en que la desalinizadora es una solución total, mientras que el trasvase es parcial. ${ }^{119}$

Aunque algunas autoridades se inclinaban por la desalinización, hubo quienes se opusieron, argumentando que la construcción y el mantenimiento de la desalinizadora costaría el doble que el trasvase. ${ }^{120}$ Roberto Romero, secretario técnico ejecutivo, consideraba inviable la desalinización porque el precio del $\mathrm{m}^{3}$ no baja de un dólar, y estos costos afectarían a los ciudadanos. "El problema es el precio de operación, que es muy lastimoso para la ciudadanía pagar recibos tan altos." ${ }^{\prime 21}$ Y respecto al estudio presentado

${ }^{118}$ Ibid., pp. 139-147.

119 "Es planta desalinizadora opción: presidente", H. Congreso del Estado de Sonora, 12 de enero de 2010

${ }^{120}$ Staff Bionero, "Dicen No a desaladora, quieren acueducto”, Bionero, 26 de enero 2010.

${ }^{121}$ Antonio Lamela señala que el aspecto económico no debería ser excusa para no llevar a cabo la desalinización, considerando que lo verdaderamente 
por el Instituto Tecnológico de Sonora, que avalaba la viabilidad del proyecto, Romero tajantemente manifestó que el estudio estaba equivocado y carente de fundamento científico. ${ }^{122}$ Para César Nava, más que inviabilidad técnica y económica, la controversia sobre la desalinizadora enmascara un conflicto entre partidos. ${ }^{123}$

Por el hecho de que el trasvase de $75 \mathrm{~mm}^{3}$ anuales afectaría a por lo menos 800000 personas que se surten de agua del Valle del Yaqui, la aprobación del acueducto fue llevada a los tribunales. ${ }^{124} \mathrm{El}$ que la aprobación del acueducto haya sido puesta a debate es indicativo de que hay una fragmentación política, aspecto que hace difícil la implementación de soluciones eficientes, porque todo queda en debates y en litigios; mientras tanto, la ciudadanía sigue padeciendo la falta de agua.

El resultado de los litigios fue a favor de la construcción del Acueducto Independencia, aspecto que nos señala que la política del trasvase sigue siendo vigente, es decir, se sigue pensando que importar agua de una cuenca a otra es una solución efectiva para la escasez y un sinónimo de progreso, porque al terminar con los problemas de agua se generará una vasta cantidad de oportunidades para la ciudadanía, sin embargo, como ya se ha señalado, un trasvase es una solución a medias y además implica transformar el entorno

costoso es carecer de agua y que en el futuro no se entenderá por qué padecimos por tanto tiempo las secuelas de la escasez de agua teniendo tanta extensión de costas. Lamela, "Desalinización”, 2004, p. 4.

122 Mago, "Muestran escepticismo en desaladora para Hermosillo", Foroson, 20 de julio de 2011.

${ }^{123}$ Nava, "Agua", 2008, p. 72.

124 "Padrés Elías: se construirá el Acueducto Independencia", La Jornada, 16 de marzo de 2012, p. 42. ecológico, social y económico de una región, y también ejercer mayor presión sobre el agua existente, por el hecho de tener que repartirla entre más personas.

\section{CONSIDERACIONES FINALES}

A lo largo de estas páginas se buscó evidenciar toda la gama de problemas y fenómenos derivados de las condiciones ambientales e históricas que han propiciado que en la actualidad la sociedad mexicana padezca los efectos de las sequías y la escasez de agua. Se hizo especial énfasis en mencionar la interrelación que guardan las malas políticas y la mala administración del gobierno para sobrellevar las sequías y para manejar las presas y cuerpos de agua, con la fragmentación política del Estado y con la utilización de soluciones parciales y de beneficios reducidos tanto en tiempo como en espacio, lo que en su conjunto nos ubica muy cerca de padecer conflictos por agua de manera cotidiana.

El presente análisis hace considerar que nuestra sociedad enfrentará grandes retos a futuro para satisfacer el abasto de agua que la ciudadanía demande; por fortuna, a escala mundial el paradigma se mueve hacia la desalinización, la cual se está convirtiendo en moneda corriente entre los expertos como la mejor opción para enfrentar la demanda futura del líquido. La desalinización ocurre de manera natural como parte del ciclo del agua, y su implementación artificial representará la última frontera de un nuevo ciclo hídrico donde ya no se dependería de las lluvias, lo cual permitirá establecer políticas efectivas para un manejo responsable de las reservas de agua, situación que finalmente solucionará muchos de los problemas derivados 
de las sequías y de la escasez. Eventualmente en nuestro país se implementará la desalinización, ¿qué tan lejano está ese futuro? Eso dependerá no de la falta de conocimientos ni de recursos económicos o tecnológicos, dependerá de la voluntad política de los gobernantes y del tiempo que tarde en establecerse un cambio paradigmático respecto a la vulnerabilidad del agua en nuestra sociedad.

\section{FUENTES CONSULTADAS}

\section{Hemerografía}

H. Congreso del Estado de Sonora.

Adnpolítico.com, 2012.

Bionero, 2010.

Centinela, 2012.

Diario de Querétaro, 2010.

Excélsior, 2012.

El Economista, 2009-2012.

El Diario, 2012.

El Diario de Coabuila, 2010.

El Financiero, 2012.

El Informador, 2012.

El Mañana, 2010.

El Occidental, 2012.

El Pueblo, 2012.

El Siglo de Torreón, 2011-2012.

El Universal, 2009-2012.

Foroson, 2011.

La Crónica, 2011-2012.

La Jornada, 2012.

La Jornada Jalisco, 2012.

La Prensa, 2012.

La Razón, 2012.

Milenio, 2011-2012.

Nosotros Diario, 2012.

Peninsular Digital, 2012.

Proceso, 2009-2012.

Punto por Punto, 2012.
Reporte Índigo, 2012.

Reuters, 2011.

Sol de México, 2012.

Vanguardia, 2012.

\section{Bilbiografía}

-Aboites, Luis, Diana Birrichaga y Jorge Alfredo Garay, "El manejo de las aguas mexicanas en el siglo Xx" en Blanca Jiménez, María Luisa Torregrosa y Luis Aboites (eds.), El agua en México: cauces y encauces, Academia Mexicana de las Ciencias, México, 2010, pp. 26-43.

-Ashton, Peter y Marian Neal, "An Overview of Key Strategic Issues in the Okavango Basin" en A. R. Turton, P. Ashton y T. E. Cloete (eds.), Transbundary Rivers, Sovereignty and Development: Hydropolitical Drivers in the Okavango River Basin, Green Cross International, Ginebra, 2003, pp. 31-63.

-Beaumont, Peter, "Water and Development in Saudi Arabia", The Geographical Journal, vol. 143, núm. 1, marzo de 1977, pp. 42-60.

-Breña Puyol, Agustín y José Breña Naranjo, "Problemática del recurso agua en grandes ciudades: zona metropolitana del Valle de México", Contactos, núm. 74, 2009, pp. 10-18.

-Cerano, Julián, et al., "Reconstrucción de 350 años de precipitación para el suroeste de Chihuahua, México", Madera y Bosques, vol. 15, núm. 2, 2009, pp. 27-44.

-Chartier, Roger, El mundo como representación, estudios sobre historia cultural, Gedisa, Barcelona, 2005, pp. 45-62.

-Chenoweth, Jonathan y Walter Wehrmeyer, "Scenario development for 2050 for the Israeli/Palestinian water sector", Population and Environment, vol. 27, núm. 3, enero de 2006, pp. 245-261.

-Clayton, R., Desalination for Water Supply. A Review of Current Knowledge, Foundation for Water Research, Reino Unido, 2011. 
-Conagua, Estadísticas del agua en México 2008, Conagua, México, agosto de 2009.

-Contreras Servín, Carlos, "Las sequías en México durante el siglo XIX”, Investigaciones Geográficas, núm. 56, 2005, pp. 118-133.

-Corona de la Peña, Claudia, "El trasvase de agua a la ZMVM desde la cuenca del Cutzamala. Centralización y rezago social”, Congreso de la Red de Investigadores Sociales Sobre el Agua, 19 de marzo de 2010, pp. 1-24.

-Dziegielewski, Ben, "The Role of Desalination in Averting a Global Water Crisis", Water International, vol. 24, núm. 4, 1999, pp. 395-398.

-Elhadj, Elie, "Household Water, and Sanitation Services in Saudi Arabia: an Analysis of Economic, Political and Ecological Issues", Water Research Group, 2004, pp. 1-22.

-Esquivel, Elizabeth, "Lluvia y sequía en el norte de México. Un análisis de la precipitación histórica en Chihuahua”, Gaceta Ecológica, núm. 65, octubre-diciembre de 2002, pp. 24-42.

-González Navarro, Moisés, "México en una laguna”, Historia Mexicana, vol. 4, núm. 4, abriljunio de 1955, pp. 506-522.

-Guerrero, Virginia et al., "El agua en la ciudad de México", Ciencias, núm. 94, abril-junio de 2009, pp. 16-23.

-Hussain, Intizar et al., "Revitalizing a Traditional Dryland Water Supply System: the Karezes in Afghanistan, Iran, Pakistan, and the Kingdom of Saudi Arabia”, Water International, vol. 33, núm. 3, 2008, pp. 333-349.

-Jiménez, Blanca et al., "El agua en el Valle de México" en Blanca Jiménez y Luis Marín (eds.), Dante Morán, Óscar Escolero y Javier Alcocer (coords.), El agua en México vista desde la academia, Academia Mexicana de las Ciencias, México, 2004, pp. 15-32.

-Kloster, Karina y Felipe de Alba, "El agua en la ciudad de México y el factor de fragmentación política”, Perfiles Latinoamericanos, núm. 29, enero-junio de 2007, pp. 137-159.
-Knighton, David, "Thirsty World”, The World Today, vol. 58, núms. 8/9, agosto-septiembre de 2002, pp. 13-14.

-Lamela, Antonio, "Desalinización (o desalación) de agua de mar”, Cuenta y Razón, núm. 130, 2004, pp. 1-13.

-Lee, Erica, "Saudi Arabia and Desalination", Harvard International Review, 2010, versión digital en <http://hir.harvard.edu/pressing-change/ saudi-arabia-and-desalination-0>. [Consulta: 25 de junio de 2012.]

-Marcos Valiente, Óscar, "Sequía: definiciones, tipologías y métodos de cuantificación”, Investigaciones Geográficas, núm. 26, 2001, pp. 59-80.

-Meulenert, Ángel, "Condiciones de sequía y precipitaciones en América del Sur durante el periodo 2004-2006", Instituto de Astronomía y Meteorología-Universidad de Guadalajara, México, 2006, pp. 1-18.

-Nava Escudero, César, "Agua y desalación en México: del engaño al oscurantismo jurídico" en César Nava Escudero y Gerardo Hiriart Le Bert (coords.), Desalación de agua con energías renovables, IIJ-UnAm, México, 2008, pp. 59-81.

-Peña, Francisco, "La lucha por el agua. Reflexiones para México y América Latina” en Pablo Dávalos, Pueblos indígenas, estado y democracia, ClACSO, Buenos Aires, 2005, pp. 217-238.

-Perló, Manuel y Arsenio González, "Del agua amenazante al agua amenazada. Cambio en las representaciones sociales de los problemas del agua en el Valle de México" en Javier Urbina y Julia Martínez (comps.), Más allá del cambio climático. Las dimensiones psicosociales del cambio ambiental global, INE-SEMARNAT/UNAM, México, 2006, pp. 47-65.

-Pineda, Nicolás, Alejandro Salazar y Mario Buenfil, "Para dar de beber a las ciudades mexicanas: el reto de la gestión eficiente del agua ante el crecimiento urbano" en Blanca Jiménez, María Luisa Torregrosa y Luis Aboites (eds.), El agua en México: cauces y encauces, Academia Mexicana de las Ciencias, México, 2010, pp. 117-140. 
-Raphael, Nicholas y Hussain Shaibi, "Water Resources for at Taif, Saudi Arabia: A Study of Alternative Sources for an Expanding Urban Area", The Geographical Journal, vol. 150, núm. 2, julio de 1984, pp. 183-191.

-Ruiz, T. y G. Febles, "La desertificación y la sequía en el mundo", Avances en Investigación Agropecuaria, vol. 8, núm. 2, junio de 2004, pp. 1-11.

-Salinas Zavala, C. A. et al., "La aridez en el noreste de México. Un análisis de su variabilidad espacial y temporal", Atmósfera, vol. 11, núm. 1, 1998, pp. 29-44.

-Selby, Jan, "The Geopolitics of Water in the Middle East: Fantasies and Realities", Third World Quarterly, vol. 26, núm. 2, 2005, pp. 329-349.

-Starr, Joyce R., "Water Wars", Foreing Policy, núm. 82, primavera de 1991, pp. 17-36.
-Velasco Velasco, Israel, "Importancia del fenómeno de la sequía” en Ángel Bravo, Homero Salinas y Agustín Rumayor (comps.), Sequía: vulnerabilidad, impacto y tecnología para afrontarla en el Norte Centro de México, Instituto de Investigaciones Forestales, Agrícolas y Pecuarias, México, 2006, pp. 5-34.

-Verbist, Koen et al., Proyecto elaboración del mapa de zonas áridas, semiáridas y subbúmedas de América Latina y el Caribe, Montevideo, 2010.

-Zarza Moya, Eduardo, "Desalinización de agua de mar mediante energías renovables" en Antonio Pascual Molina (coord.), Actas del I y II Seminario del Agua, 1997, pp. 199-226.

-Zhou, Yuan y Richard S. J. Tol, "Evaluating the Costs of Desalination and Water Transport", Water Resources Research, vol. 41, 2005, pp. 1-16. 